April 1999 • NREL/CP-520-25770

\title{
Light-Trapping in a-Si Solar Cells: A Summary of the Results from PV Optics
}

B.L. Sopori, J. Madjdpour, W. Chen, and Y. Zhang National Renewable Energy Laboratory

Presented at the National Center for Photovoltaics Program Review Meeting

Denver, Colorado

September 8-11, 1998

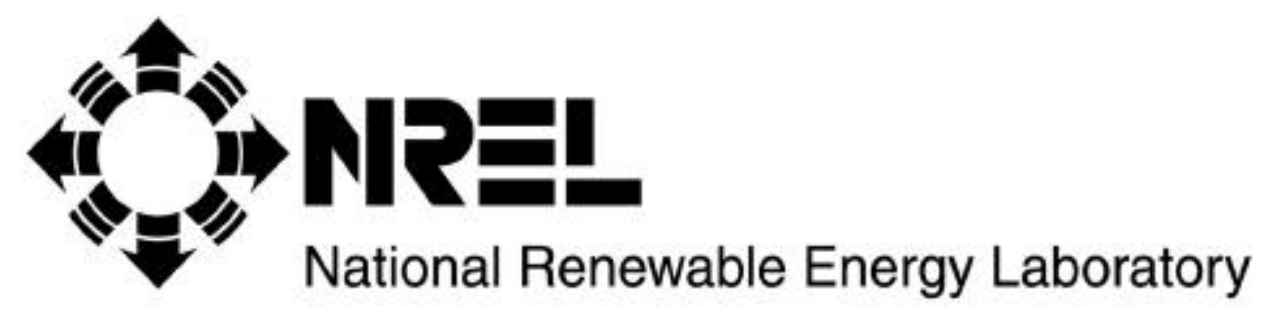

1617 Cole Boulevard

Golden, Colorado 80401-3393

NREL is a U.S. Department of Energy Laboratory

Operated by Midwest Research Institute $\cdot$ Battelle $\bullet$ Bechtel 


\section{NOTICE}

This report was prepared as an account of work sponsored by an agency of the United States government. Neither the United States government nor any agency thereof, nor any of their employees, makes any warranty, express or implied, or assumes any legal liability or responsibility for the accuracy, completeness, or usefulness of any information, apparatus, product, or process disclosed, or represents that its use would not infringe privately owned rights. Reference herein to any specific commercial product, process, or service by trade name, trademark, manufacturer, or otherwise does not necessarily constitute or imply its endorsement, recommendation, or favoring by the United States government or any agency thereof. The views and opinions of authors expressed herein do not necessarily state or reflect those of the United States government or any agency thereof.

Available to DOE and DOE contractors from:

Office of Scientific and Technical Information (OSTI)

P.O. Box 62

Oak Ridge, TN 37831

Prices available by calling 423-576-8401

Available to the public from:

National Technical Information Service (NTIS)

U.S. Department of Commerce

5285 Port Royal Road

Springfield, VA 22161

703-605-6000 or 800-553-6847

or

DOE Information Bridge

http://www.doe.gov/bridge/home.html 


\title{
Light-Trapping in a-Si Solar Cells: A Summary of the Results from PV Optics
}

\author{
B. L. Sopori, J. Madjdpour, W. Chen, and Y. Zhang \\ National Renewable Energy Laboratory \\ 1617 Cole Boulevard, Golden, Colorado
}

\begin{abstract}
This paper describes major features of a new optical software package, PV Optics, and presents a brief summary of the results of applying this program to analyze amorphous silicon solar cells. Some examples are given, mainly to demonstrate the nature of calculations that can be performed with this program for a-Si cell design.
\end{abstract}

\section{INTRODUCTION}

The current designs of amorphous $\mathrm{Si}(\mathrm{a}-\mathrm{Si})$ solar cells have overcome a major problem associated with the Staebler-Wronski effect by going to thinner and multi-junction designs(1). However, thinner cells require very effective light-trapping. The most common way to incorporate light-trapping is to use a textured, transparent conductor in the superstrate-type cells, and a textured metal in substrate-type cells. Subsequent thin-film depositions carry this texture through the entire structure in a conformal manner. Use of texturing and many other design features in the current cells is very difficult or even impossible to handle by simple optical analysis. These features include (i) nonplanar interfaces; (ii) a combination of thick and thin layers; (iii) multiple semiconductors of different optical properties; and (iv) dielectric and metal coatings. More-mature numerical analysis tools are needed to deal with the optical design and analyses of these cells and modules. In this paper, we describe some important features of a new software, $P V$ Optics(2), and briefly discuss its applications to a-Si solar cell analysis and design.

\section{FEATURES OF PV OPTICS}

PV Optics is applicable to optical design and analysis of thick cells, thin cells, and modules. It is capable of:

- Analyzing device design with as many as three active semiconductor layers, plus a glass cover, encapsulation, antireflection coating, buffer, and metal backing. 
- Calculating photon absorbance as a function of depth and maximum achievable current density (MACD) within each semiconductor layer.

- Calculating reflection, transmission, and absorption spectrum and metal absorbance as a function of wavelength.

- Outputing the results in a format compatible with any commercial graphical packages.

$P V$ Optics allows a very simple means of setting up a desired cell configuration and defining the input parameters to desired values with a simple click of the mouse, and records of each run can be saved for future analysis. The results can further be used in an electronic model like AMPS(3) or PC1D(4) for complete cell-performance prediction. It offers a choice of direction of light illumination of the solar cell for ease of dealing with both superstrate- and substrate-type cells. PV Optics can be used not only for the analysis, but also, for effective design of a solar cell. One can optimize parameters such as thickness, textures type, antireflection coating, and metallization for any cell.

\section{OPERATING PRINCIPLES OF PVOPTICS}

PV Optics is designed to handle wafer-based cells, as well as thin-film cells. Its sophisticated model uses the coherence length of light as a criterion to categorize various regions of a cell as "thin" or "thick" — the former have thicknesses less than the coherence length of light and include interference and polarization effects; the latter are much thicker than the coherence length and are treated on the basis of ray optics. The model separates a multilayer structure into several composite layers, each as a "thin" or "thick" group. Each group of layers is analyzed, and the entire structure is reassembled. Regions such as glass superstrates or encapsulation layers having thicknesses greater than a few microns, as well as textured structures, are treated in a non-coherent regime. Thin and specular layers, such as those used for antireflection (AR) coatings and in thin-film a-Si devices, are treated as coherent regions.

Figure 1 is a schematic illustrating the methodology of performing noncoherent calculations. This figure shows a beam of unit intensity that is incident on a sample that has an arbitrary surface morphology. The beam is split into a large number of beamlets that impinge on a small region of the surface. Each beamlet is allowed to propagate within the sample, and we keep track of its entire path while it undergoes reflections,

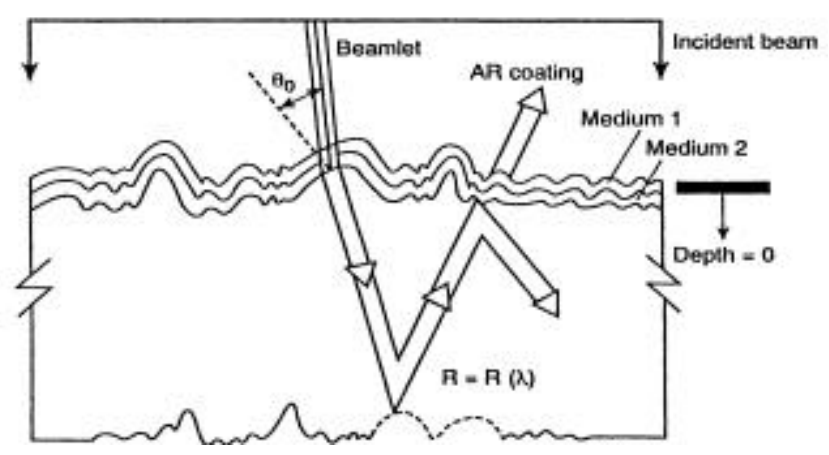

FIGURE 1. A schematic illustrating the methodology of performing light-tracing calculations. 


\begin{tabular}{|c|c}
\hline Glass & $100 \mathrm{Mic}$ \\
\cline { 1 - 1 } $\mathrm{SnO}_{2}$ & $0.9 \mathrm{Mic}$ \\
\cline { 1 - 1 } $\mathrm{a}-\mathrm{Si}$ & $\mathrm{Mic}$ \\
\hline
\end{tabular}

(a)

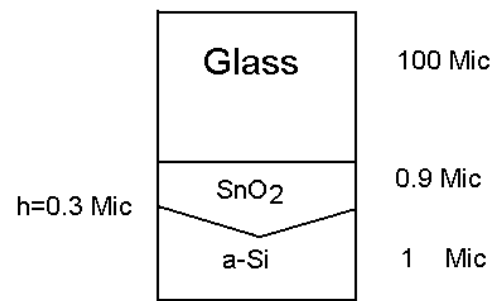

(b)

FIGURE 2. Schematics showing the structures used for calculations.

transmission, and absorption, until the energy in the beamlet reaches a predetermined (negligible) value. MACD is calculated by adding the total absorbance corresponding to an AM1.5 input spectrum. In the case of a multijunction device, the absorbance in each layer is calculated to determine MACD for each junction.

\section{RESULTS}

In this section, we present results of calculations for a number of cell and module structures. To illustrate $P V$ optics' ability to handle non-planar interfaces, we start with calculating the optical properties of the simple structures shown in Figure 2a and 2b. Both of these structures have three layers: glass $/ 0.9-\mu \mathrm{m} \mathrm{SnO}_{2} / 1-\mu \mathrm{m}$ a- $\mathrm{Si}$; the only difference is that there is $0.3-\mu \mathrm{m}$-high texture at the $\mathrm{SnO}_{2} / \mathrm{a}-\mathrm{Si}$ interface in the structure of Figure $2 \mathrm{~b}$. The light is normally incident from the glass-side of each structure.

Figure 3a shows the calculated reflectance, transmittance, and absorption as a function of wavelength of these two structures, based on non-coherent analysis. As expected, in the wavelength range of visible light, the reflectance of the structure with interface texture is lower, whereas its absorption is higher than that of the non-textured structure; in the wavelength range greater than $0.7 \mu \mathrm{m}$ the reflectance behavior is reversed. These features

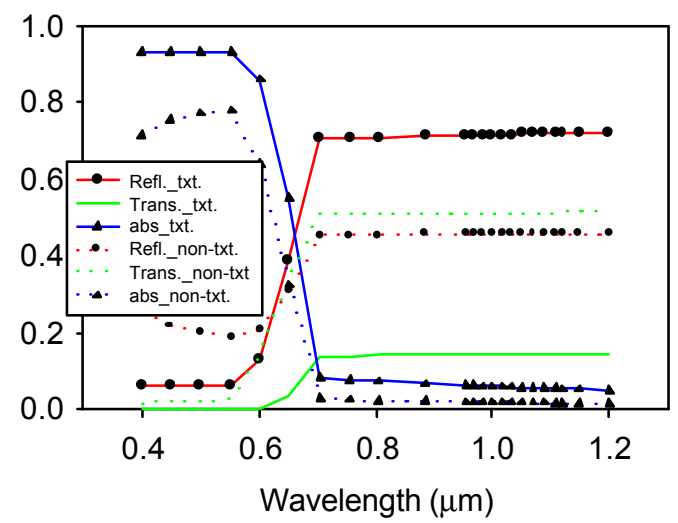

FIGURE 3a. Comparison of the calculated optical properties and MACD of two cell structures shown in Figure 2.

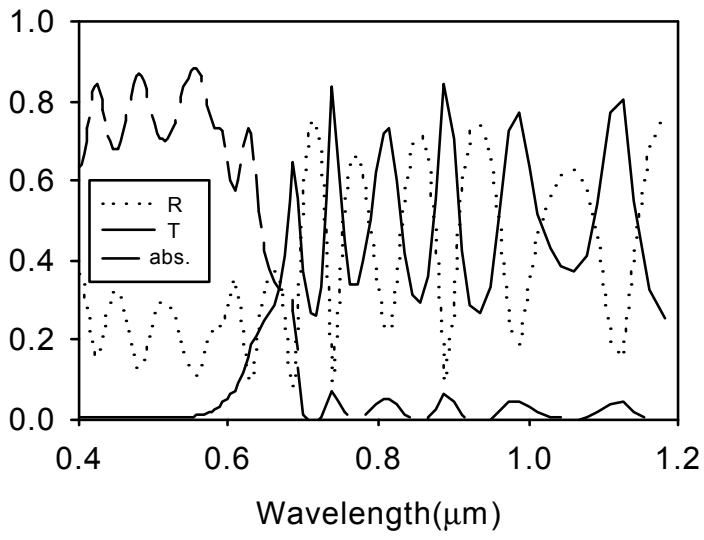

FIGURE 3b. Calculated reflection, transmission, absorption of structure showed in figure $2 \mathrm{a}$ based on the coherent mode. 
result in a higher MACD $\left(16.64 \mathrm{~mA} / \mathrm{cm}^{2}\right)$ for the textured structure vs. $12.03 \mathrm{~mA} / \mathrm{cm}^{2}$ for the planar structure. As indicated earlier, PV Optics recognizes the coherent and the noncoherent nature of a structure. Figure $3 \mathrm{~b}$ shows the results of the calculation for the structure $3 \mathrm{a}$, using coherent calculations - the generation of interference fringes due to thin $\mathrm{SnO}_{2}$ and a-Si is observed.

For the next example, we consider two structures representing triple-junction cells, as shown in Figures 4a and 5a. These two structures have three semiconductor layers (a-Si-T,

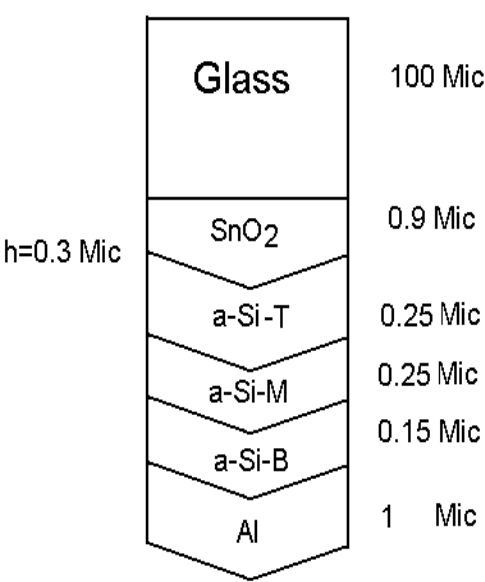

FIGURE 4 a. Structure used for calculations.

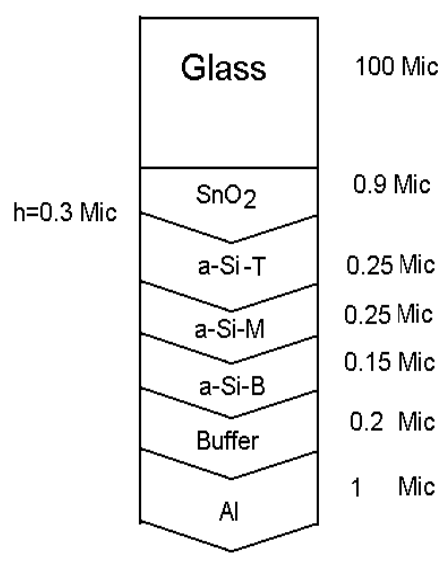

FIGURE 5 a. Structure used for calculations.

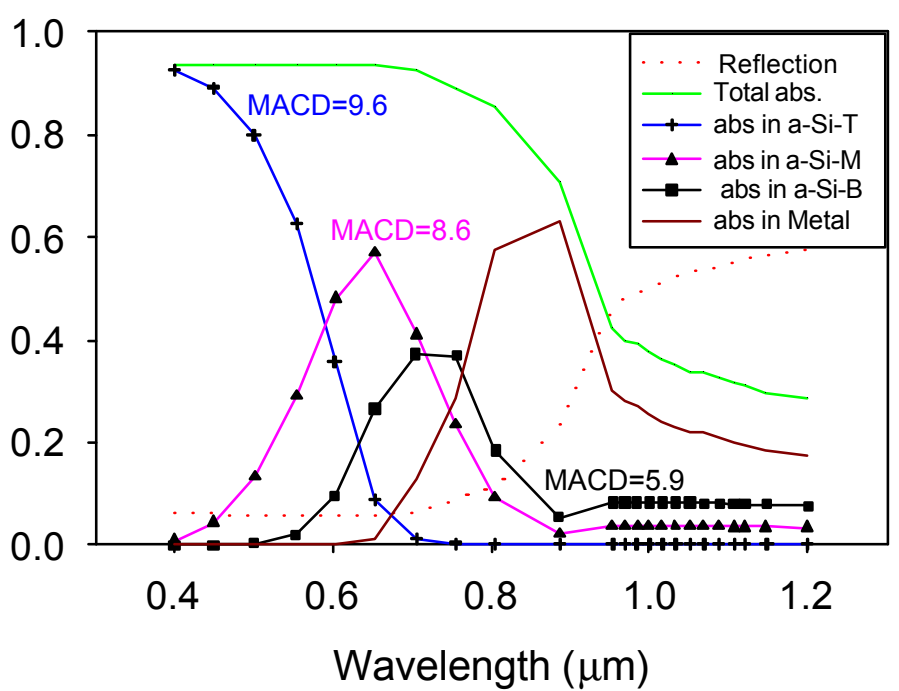

FIGURE 4 b. Absorbance as a function of wavelength within each layer of the structure shown in Figure 4a. The total metal loss $=9.8 \mathrm{~mA} / \mathrm{cm}^{2}$.

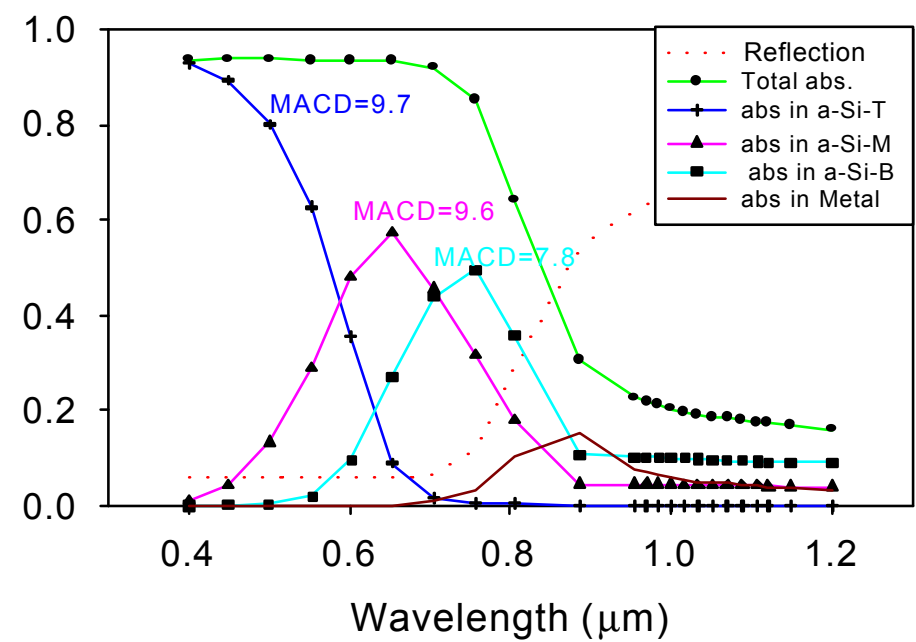

FIGURE 5 b. Absorbance as a function of wavelength within each layer of the structure shown in Figure 5a. The total metal loss $=3.1 \mathrm{~mA} / \mathrm{cm}^{2}$. 
a-Si-M, and a-Si-B, for top, middle, and bottom cells, respectively), AR coating, Al backcontact, and glass encapsulation. The structure in Figure 5a has a $0.2-\mu \mathrm{m}$-thick buffer layer inbetween the a-Si-B and Al. The Figures $4 \mathrm{~b}$ and $5 \mathrm{~b}$ show the calculated reflection, total absorption, absorption in each a-Si layer, and metallic absorption of the structures shown in Figures $4 \mathrm{a}$ and 5a, respectively. From these figures, we see the following: (i) there is strong absorption in metal layer without buffer; the metal loss can be reduced dramatically, from $9.8 \mathrm{~mA} / \mathrm{cm}^{2}$ to $3.1 \mathrm{~mA} / \mathrm{cm}^{2}$, by adding a buffer layer, (ii) the bottom cell gets the most benefit from the buffer. The absorption in it increases along entire the wavelength range, and its MACD increases about $32 \%$ (from $5.9 \mathrm{~mA} / \mathrm{cm}^{2}$ to $7.8 \mathrm{~mA} / \mathrm{cm}^{2}$ ), whereas the MACD of the top a-Si layer increases only about $1 \%$, (iii) the reduction in the metal absorption by the buffer layer is considerably more than the increase in the total absorption of the entire device.

The third example, we consider the effect of changing the thickness of the bottom cell on the photocurrent from each cell in a configuration of Figure $4 \mathrm{~b}$. The results are shown in Figure 6a. We see that the dominant change due to increasing the bottom-cell thickness is in the photocurrent of the bottom-cell, with some reductions in the middle and the top cells. The metallic loss, associated with the changes in the bottom-cell thickness, is shown in Figure 6b. As expected, the loss decreases with increase in the bottom-cell thickness. These results can be qualitatively understood by recognizing that an increase in the bottom cell thickness reduces the light intensity at the bottom-cell/Al interface, with a concomitant reduction in the light reflection.

\section{CONCLUSIONS}

The examples illustrated in this paper indicate of the capabilities of PV Optics. Some general conclusions can be made:

1. Light-trapping is essential in thin cells. Texturing the substrate or the superstrate is an effective way to include light-trapping in an a-Si solar cell. We have assumed conformal texturing initiated by texturing TCO or the substrate for superstrate or the substrate configurations, respectively.

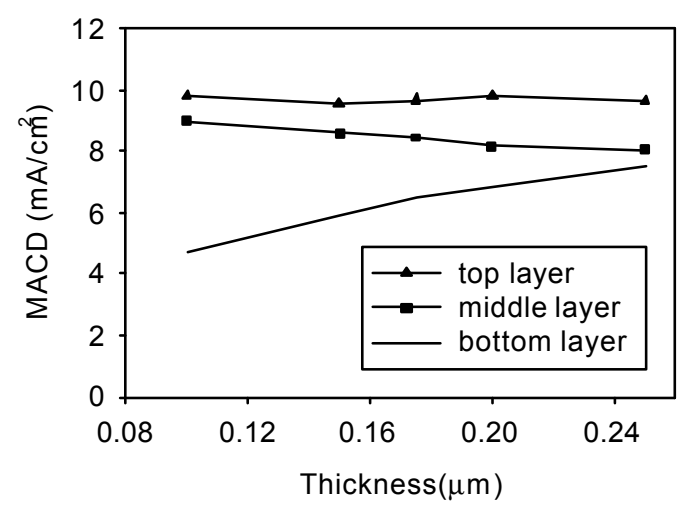

(a)

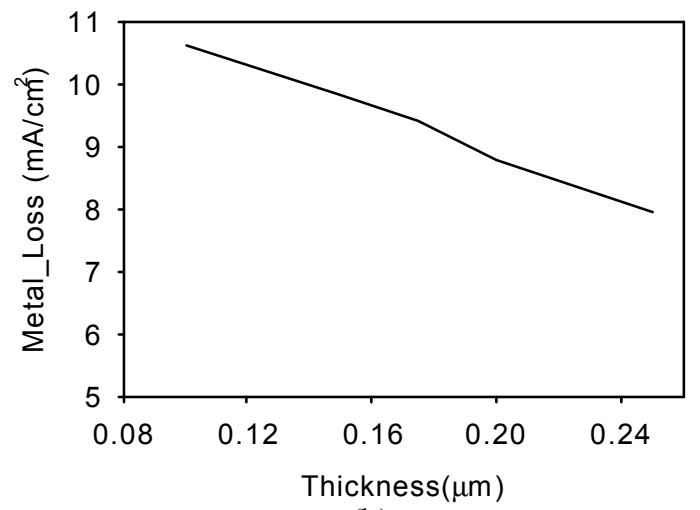

(b)

FIGURE 6. (a) Effect of the bottom cell thickness on the MACD of each cell, and (b)on the metal loss. 
2. Metallic reflectors can introduce substantial losses. This loss can be reduced by introducing a buffer region, consisting of a low-refractive-index material between the semiconductor and the metal. In general, an increase in the buffer thickness leads to lower metallic loss.

3. We have seen that the use of a back-reflector affects the bottom-cell current most and the top-cell current least. This behavior can be used in developing the current matching conditions for a multi junction device.

4. Antireflection effects of the TCO can be quite effective. Texturing makes AR effects very broadband.

5. Texturing must provide both reduced reflectance, as well as an increase in the absorption. As a general rule, it is preferred to incorporate texture at an interface that is close to the front of the cell. This allows minimization of the first cell thickness.

6. Having a non-conformal texture, in which the metal-semiconductor interface can be planar, can minimize the metal loss. Increasing the metal-semiconductor area increases the absorption in the metal.

\section{ACKNOWLEDGEMENT}

This work was supported by the U.S. Department of Energy, under Contract No. DEAC36-83CH10093.

\section{REFERENCES}

1. D. L. Staebler and C. R. Wronski, Applied Physics Letter, 31, pp. 292 (1977)

2. B. L. Sopori, Laser Focus, 34, pp159-161, Feb. (1998).

3. AMPS is a software developed by Penn State University and is available through Prof. S. Fonash.

4. D. A. Clugston and P. A. Basore, "PC1D Version 5: 32-bit Solar Cell Modeling on Personal Computers", in Procd. of $26^{\text {th }}$ IEEE Photovoltaic Specialist Conference - 1997, pp. 207 (1997) 